\title{
THE IMPACT OF EMERGING INFORMATION COMMUNICATION TECHNOLOGY IN THE PORT: INCREASING UTILITIES RENDERING TO SHARED VERDICTS
}

\author{
Biplab Santra ${ }^{1}$, Prof. ( Dr.)Kamal Kumar Bardhan ${ }^{2}$ \\ ${ }^{1}$ Research Scholar, School of Management, Techno India University, WB \\ ${ }^{2}$ Professor, School of Management, Techno India University, WB
}

Article DOI: https://doi.org/10.36713/epra9275

DOI No: 10.36713/epra9275

\begin{abstract}
Today, transportation quantities on roadways have increased to the point where alternate forms of transportation are required. Sea Routes Transportation (SRT) is one option that has the potential to assist relieve traffic congestion on roadways. Most SRT systems employ vessels in which cargo is rolled on and off by a ramp with relatively limited capacity, often less than $500 \mathrm{TEU}$, however with increased cargo flow, it is unclear if such alternatives will be economical. The dilemma for ports participating in SRT to face this new massive change is to make suitable expenditures and analysis software. Transition is not just a current trend, as well as a structured process. That modification could not be avoided by excluding ports. A transformation project has begun in order to modify their operating structure as well as the services they provide. Artificial intelligence and data-driven services expand the landscape of services far beyond conventional models now in use. The purpose of this study is to examine and assess the new potential for Telecommunications/Information and Communication Technology (ICT) companies at port facilities. These prospects are a first step in transforming ports for the long term. The research's important component is the application of technology science approaches in the area of strategy and planning connected to the construction of components systems (e.g., interrelations among ships and materiel) with managing equipment selections.
\end{abstract}

KEYWORDS: Information and Communication Technology (ICT), Port, Sea Routes Transportation (SRT)

\section{i. INTRODUCTION}

As far back as ancient times, ports have been the places where land and sea freight transportation came together, and they still are today. The first ports were built near cities, and they were used as a gateway for people to move goods between them. It has worked for a long time, so these ports are understood as firstgeneration ports. Mid-20th century: Some ports were built from the ground up near large industrial areas, providing business or manufacturing services to the plants. This is how it worked: In this port, we look at the second category of ports. During the last decade of the twentieth century, 3rd ports started to appear. This was mostly due to global large-scale containerization and the growing needs for international trade. In the past few years, ports have become transportation hubs and logistics centres. Economically, ports add value to goods that move through them because of both their location and the changes that are made to the items while they're there (UNCTAD, 1994; UNCTAD, 1999; Russo and Musolino, 2020). It was at the turn of the century that bigger ships, alliances between businesses, and common access to the hinterland made it more important for some ports near each other to build new facilities. Some ports can't keep up with the competition, which means they need enough money to keep up (Inoue, 2018). At the very least, it's not smart to add or duplicate facilities and equipment in ports in the same region that aren't being used. As a result, ports that were closer together started working together instead of competing (Martn-Alcalde et al., 2016). There were a lot of different alliancemerging methods used, and that led to the four-generation ports.

During the early stages of technological development in ports, it was shown that, in addition to being near a city or a light industry plant, ICT (Information and Communication Technology) is another important part of port innovation that adds value to the services and infrastructure provided (Heaver et al., 2010; Carlan et al., 2016). In the next few years, the fifth generation of ports will start. Using stand-alone ICT helps solve problems that arise when people make money and communicate. People who make decisions become more efficient with these tools, but they don't deal with the relationships between people who make them. Contacts are important 
for the port's three main flows: cargo, information (Gattuso et al., 2005), and financial transactions. They help clear authorization and permission (Carlan et al., 2020). The various generation diagram of port service is presented in Figure.1.

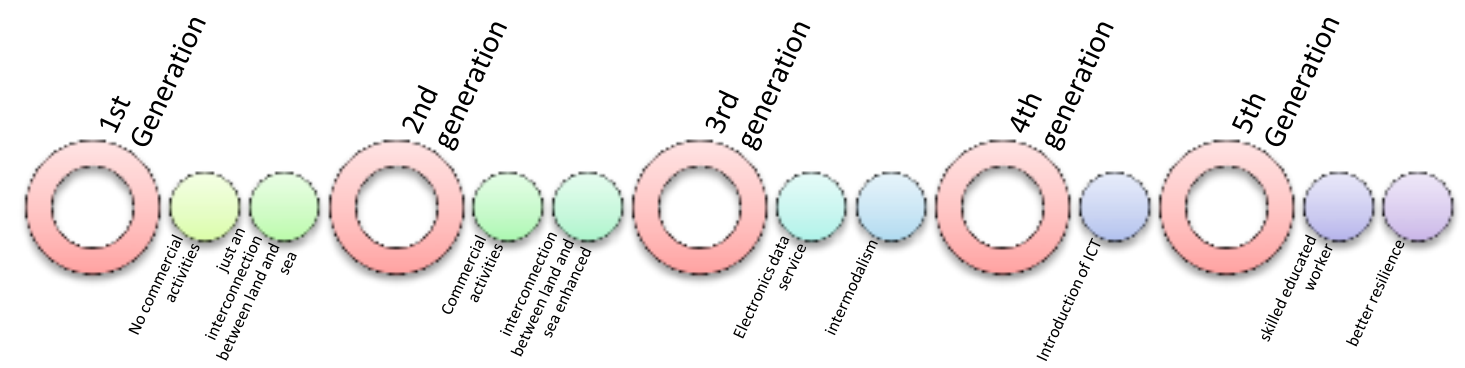

Figure.1. Stages of port developments

In terms of how things move, cargo management is all about exchanging data so that ships and port infrastructure can work at their full capacity (such as quays and yards). It gets more and more complicated to move from a huge amount of freight on a single ship to a lot of different containers on a lot of different provenance couples on every single ship. The classical theory of management doesn't work well with this kind of volume, which leads to low-use ships and container terminals (e.g., quays and lawns). (Turgut,2015) It's so bad at communicating about authorization flows that international banks give each country a grade in the Logistic Performance Index. This is mostly because old manual solutions are so bad at a higher level (The World Bank, 2018). The configuration of a port system is presented in Figure.2.

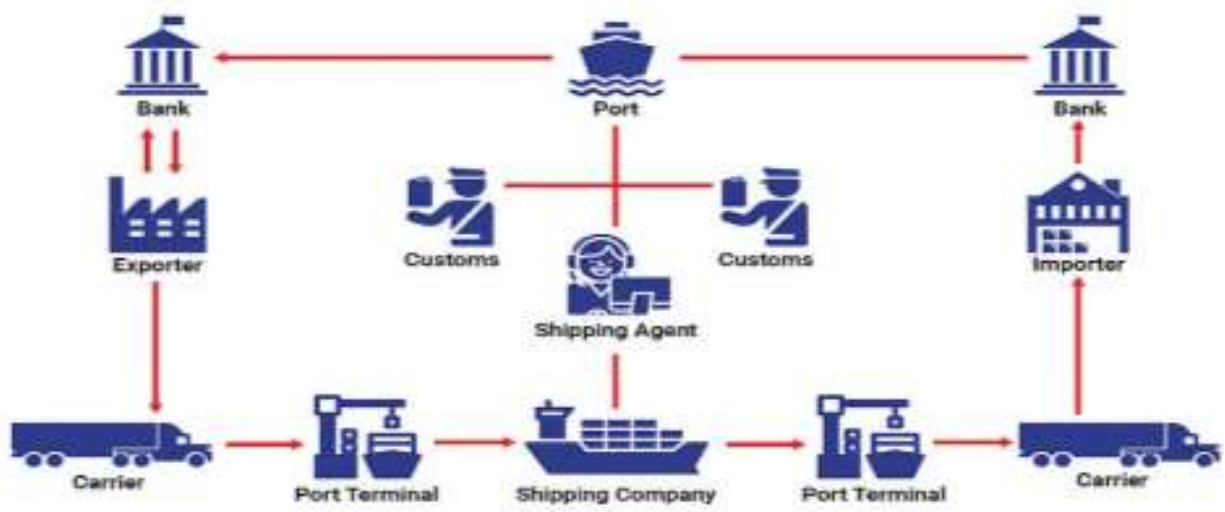

Figure.2. Working of the port system

This is the third type of migration that takes place at the port: capital assets. Ports are particularly vulnerable to economic interactions between countries, with different bank laws causing delays in making comparisons funds and releasing the confirmation of transactions because of the nature of the goods that come from outside the country. It will focus on ICT-related technologies, not automation and AI, which could cut down on the time it takes to handle a Unit of Load (package) (UL). It turns out that smart machines only have an impact on people who make decisions about how goods move. There are ways to cut the time it takes to move things around, like by switching from tower cranes to autonomous drone transtainers.

The functionalities of the Transportation Management Systems (TMS) make it possible to use all of the new ICT tools to their fullest potential (Caldeirinha et al., 2020; Moros Diaz et al., 2020). These people want to make it easier for everyone to work together and for society to stay alive. There are a lot of things that make it 
possible for people to work together: the integration of messaging services, as well as the sharing of knowledge and supporting documents between decisions. Ten years ago, sophisticated ICT technologies were brought into ports, first as self-contained DSSs (Decision Assist Systems) that helped cargo flow, and then as cooperative PCSs (Cooperative PCSs) that helped cargo flow. This is how it worked: Today, new technologies are setting a new standard for ports. Because documentation and accounting systems are so important in ports, there are a lot of people who make decisions about how to run the port. Solving administrative and financial problems takes a lot longer than actually moving goods. Today's growing use of ICT is very important because it helps cut down on the time it takes to do administrative and financial tasks. This allows multiple people who work together to come up with the best possible solutions.

The Transport System Models (TSMs) equations are used to make a theoretical model of the problem. Here, we look at how to make a supply model that fits the way a port is run, how to figure out who the decisionmakers are, what demand looks like, and what and one of the most common types of decisions that happen in ports are. Innovative technologies are then brought back, which allows people to make decisions together and thus lowers overall costs (time). Each person who makes decisions about how to run a port has made his or her own ICT system. In general, the more private certain ICT systems are, the less likely they will be shared with other people who make decisions about how to use them. Using a new method, the organization can fully integrate new technologies into its work while also protecting its data and making it hard to work with other ICT systems (or impossible). At the same time, different people make decisions about how goods, knowledge, and money move through different parts of the world. These people, who are often in opposing roles, are in charge of these separate flows. Simulation Port Operations shows how port operations, tends to flow (from the segments), and judgement call are all linked together in a way that makes sense. In this frame - work, emerging ICTs play an important role in cost functions. This makes it easier to think about and evaluate different ICT scenarios that have different levels of group decision among the people who make them. TSM is the theoretical model that can be used to look at the introduction of new ICT. This model can be used to look at how people use new ICT. On the Deterministic Consumer Equilibrium Model, you see how a port system looks when it has shared ICT and when it does not. There should be more research into how cost functions can be calibrated with different levels of influencing decisions, helped by ICT, in real-world situations. The example's findings are very interesting.

Unique to this article is that it can use TSM math to look into the benefits of ICT systems in ports and figure out how much money they could save. We can find and build new ports because emerging ICTs can make them more useful.

\section{ii. INFORMATION AND COMMUNICATION TECHNOLOGY (ICT)}

Information and communication systems are critical components of container terminals operations. Information systems have been defined as the mechanism through which supply chain elements are interconnected (T. Higgins et al February 1999). As TEU capacity grows, the complications associated in recognising and handling containers must be handled with ICT technology. As a result, effective information flow for container ports has a higher potential for increasing production. "The interchange or non-sharing of information beforehand, throughout, but after a procedure has a substantial effect on the effectiveness" (J. Törnquist \& I. Gustavson, 2004). As a result, strategies targeted at optimizing the choosing of processing equipment's can take advantage of the potential afforded by ICT technology, particularly in tracking service to run methods, i.e. effective information technology management (ITM) can increase the usage of optimization models. It may be feasible to enhance information flows in container ports if they are properly managed (T. Higgins et al February 1999). The Fig.3. Illustrate the feasibility constraints (Date,2021) 


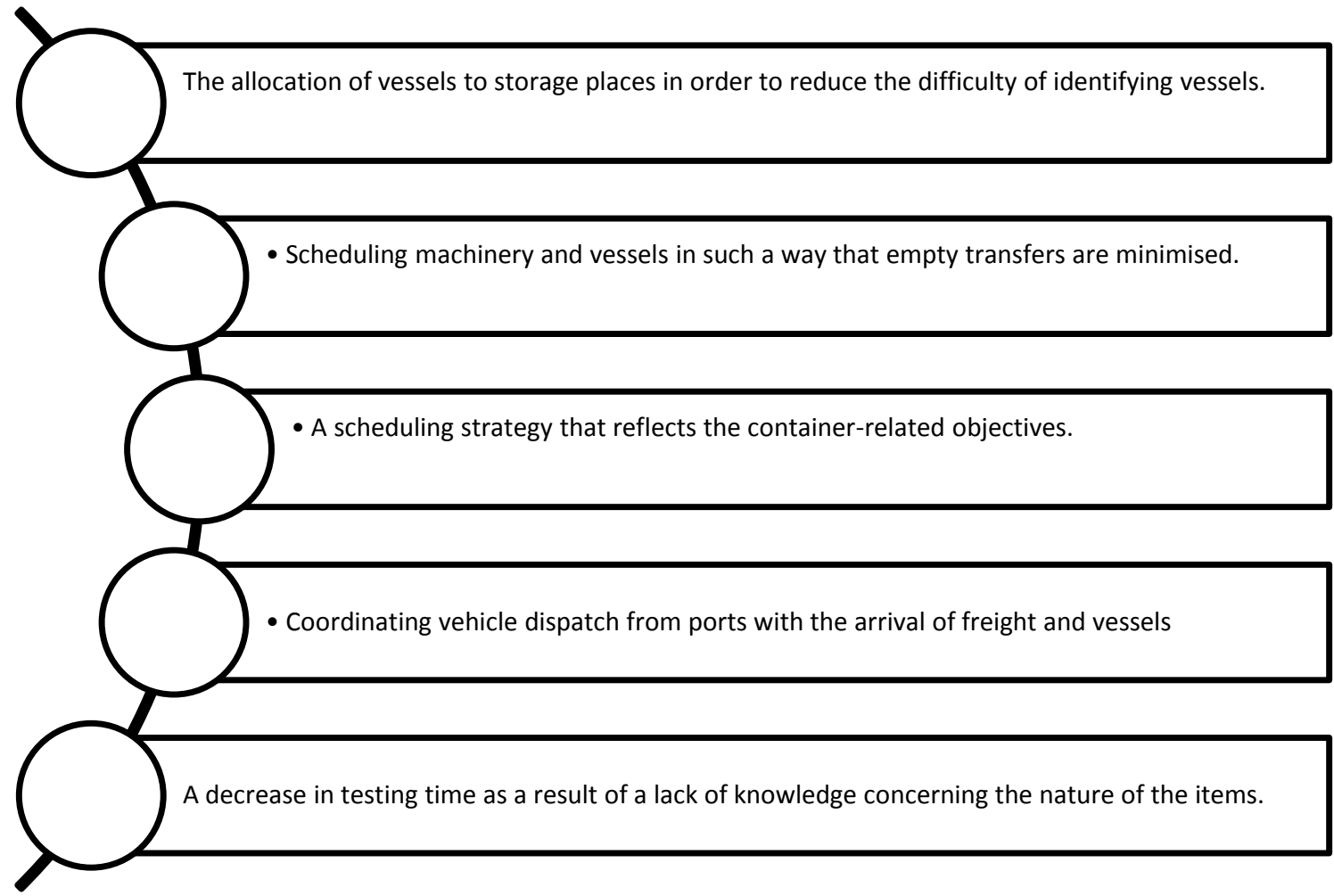

Fig.3. Feasible to enhance information flows in container ports

Despite numerous attempts and have already effective implementations of Ict skills in port facilities (e.g., Navis, OPTIMA, etc.), the seagoing business in overall, as according T. Higgins et al February (1999), has yet to fully exploit automatic vehicle entering data innovations in accomplishing the legitimate goal. One conceivable motivation is the need for all collaborators in the entire supply chain to actually engage in the use of methods commonly with benchmarks in the case of connectors involved in frequency shipments is the requirement for all collaborators in the entire supply chain to fully engage with the use of methods commonly with norms. For illustration, a terminal that invests in wireless radio innovation technologies may have issues while dealing with a terminal or shipment line that employs bar codes.( Awada, 2006)

Within the marine business, ICT technology may be categorized into the following groups as presented in Fig.4., as per G.A. Giannopoulos (2004): 


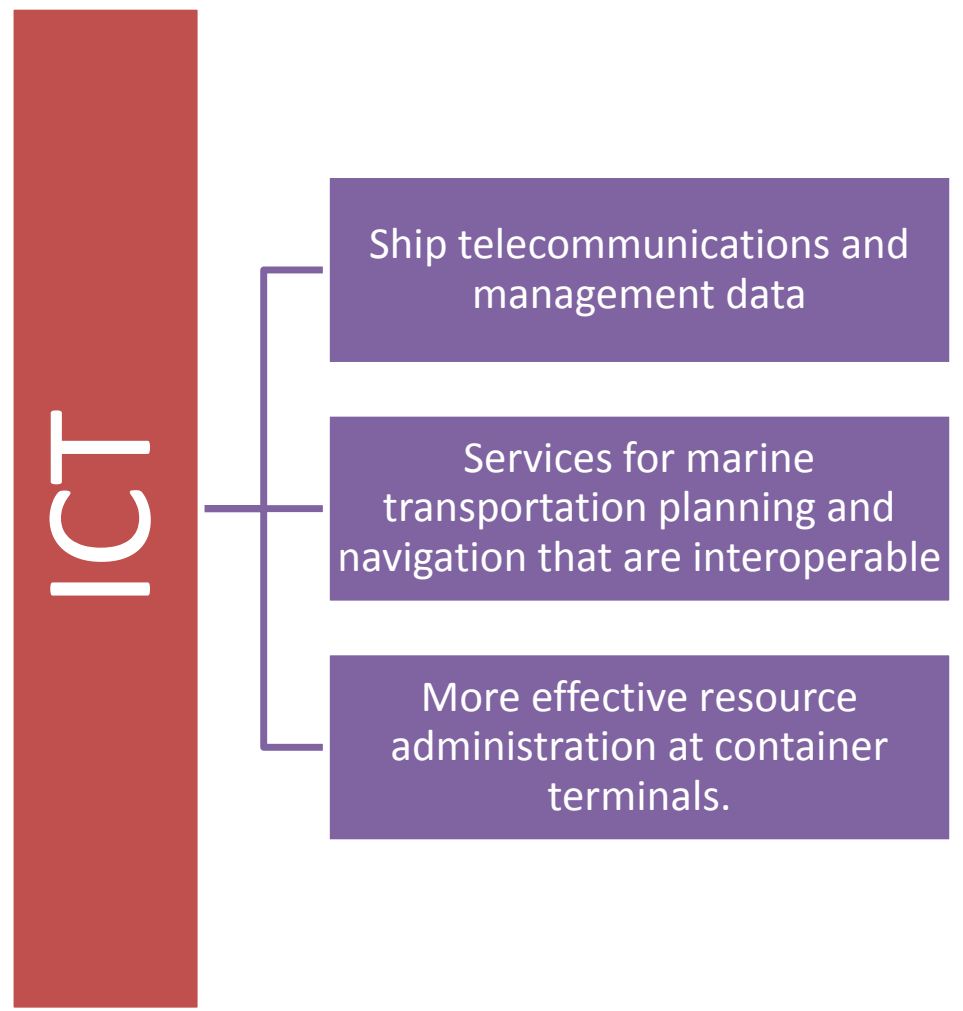

Fig.4. Categorization of ICT

\section{Ship telecommunications and management data}

The vessel system is becoming more integrated and dispersed as ship technology advances. Though various ships have varied roles, all formulations of a Ship Information Arrangement (SIA) published in research have one crucial aspect in common. This distinguishing characteristic is that SIA is made up of numerous separate sub networks (wireless sensor, presentation systems, and etc) and a whole ship network connectivity that can effectively communicate (reference inputs, plant result, control input, and etc) across subnet mask and subsystems. Figure.5. shows the Ship Information Arrangement.

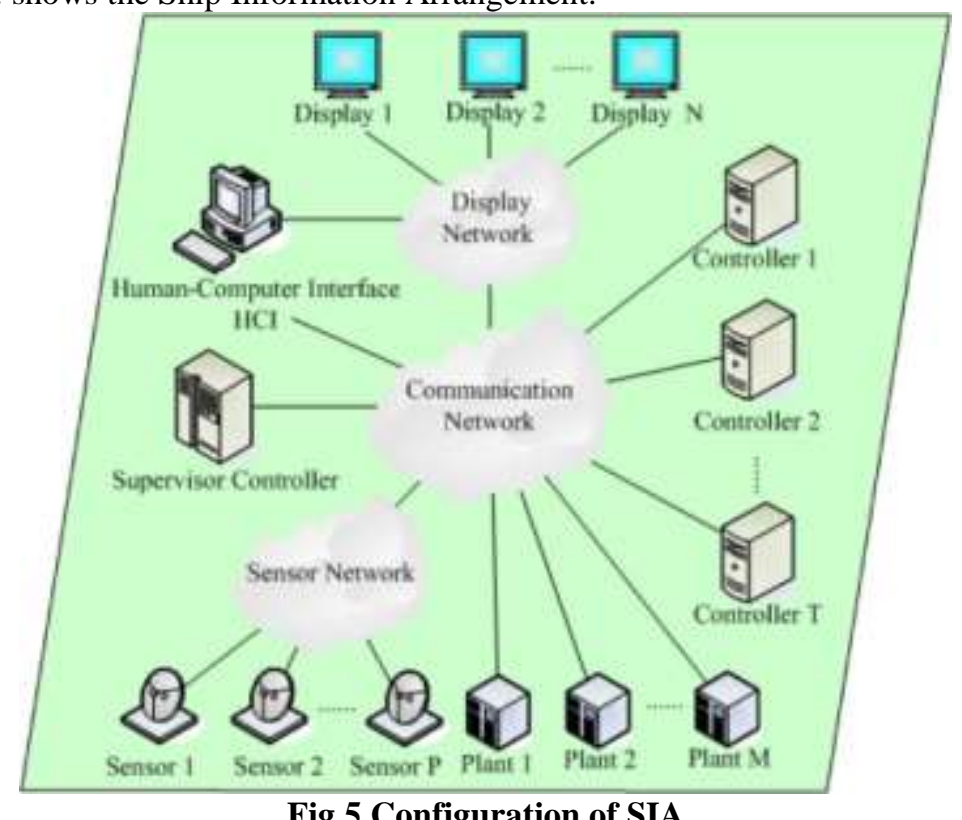

Fig.5.Configuration of SIA

traditionally, electrical transmission on ships relied on point-to-point wire to exchange data. Wiring a vessel had become a logistical headache given the recent fast expansion in the quantity and variety of onboard electrical gadgets. In this scenario, shipbuilders and maritime electronics manufacturers replaced traditional wire with contemporary local area network ( lan. Martin et al. reviewed and examined certain early naval data 
management systems, including the Seagoing Data Multiplexer System (SDMS) and the dispersed switch network "SITACS," which might be considered transitions to SIAs.

\section{iii. Smart Port facilities}

Technology and applications that is smart in Smart Port facilities. The key to making a port smart is to use connected latest technology in a way that is useful. Ports will be able to use big data, AI, IoT, and other technologies to get actionable information from the data they collect. 5G will help even more people use IoT. The various smart port initiation is presented in Figure.6.

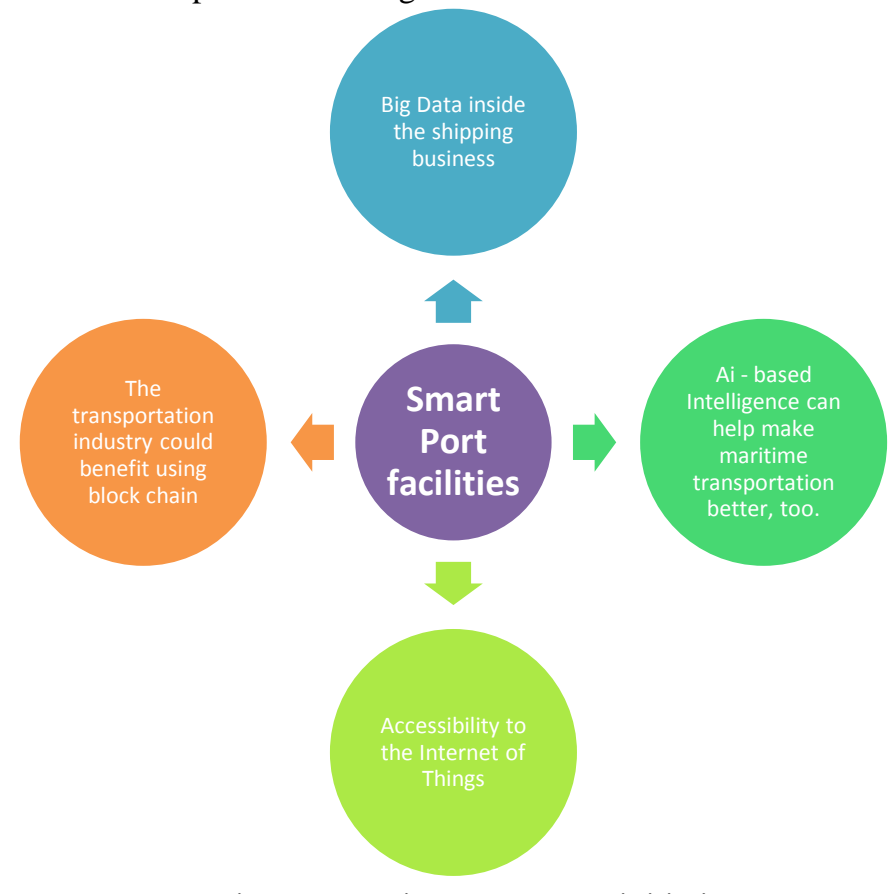

Figure.6. Various smart port initiations

\section{Big Data inside the shipping business}

To continue improving their transportation and become smarter about ports, the transportation industry will be able to use a lot of big data sets.

Thus according Marine Multimedia, cloud computing is used to manage a ship's sensors and do pattern recognition, which is important to avoid interruptions and improve the efficiency of the industry as a whole. In the shipping business, it is very important to be able to track cargo properly in order to keep things safe and private.

Classical innovation has been used by businesses for a long time, allowing them to analyse huge amounts of data from conventional channels like warehouses and logistics operations. This innovation has been used for a long time. When you use big data, it takes it to the next level. It will make it easier for businesses to use a lot of different types of data, like text, sound recording, and video, as well as knowledge from business applications, in both batch but instead real-time ways. It's important to know why you can care about cloud computing in shipping and what big data is in transportation. Big data deals with a lot of data. This data is relevant if you will be shipping the commodities as a seller or getting them as a customer.

\section{AI - based Intelligence can help make maritime transportation better}

A lot of the time, AI is used to talk about Machine Learning, which is when computers get better at things over time. As a result, the computers use algorithms that will get better with time. AI, for example, can be used in the transportation industry to improve shipping routes. AI can figure out the best way to go at the best speed.

\section{Accessibility to the Internet of Things}

Wireless connectivity networks are used to connect sensors and devices that are built into physical objects to each other. loT helps the maritime industry cut costs, make it easier to measure and analyze cargo, and more. With loT interconnections, port operators will be able to make smart decisions based on data. This will make ports "smart." Because of the use of Distributed ledger technology, shipping will be faster. In the shipping business, IOT technology might be a very good thing to have. It should be able to work with some other technologies, like IoT, digitization, and big data, so that they can all work together.

\section{The transportation industry could benefit using block chain}

This could speed up shipping and give them better information about what people want and how much they want. Blockchain, which is a type of digital ledger technology, could be used to plan and control the trail of 
evidence of countless thousands of containers around the world. In 2017, Maersk and IBM built a distribution network called TradeLens that runs on the blockchain. It was built in 2017. Network: "This digital shipping network is made up of the biggest carriers, port technicians like the Port area, and other people who work in the international freight supply chain."

There are many good things about using blockchain for shipping. It would be better for the shipping industry to use blockchain because it would make the system more open and not have to deal with a lot of paper work. Using blockchain for shipment is a good idea, says ProShip, a multinational company of automated number of co shipping operating system. The advantages are almost too many to list. They include faster processing times, lower costs, and superior customer service. A lot of people are excited about 5G because it lets people connect with each other in many different ways. $5 \mathrm{G}$ will contribute to make phone and video communications better. Inventory control will be better off when data moves faster and in real time. It would communicate all the people in the supply chain, which is what it would do.

"5G networks will be much more electricity, which means that all kinds of connections can be made with less actual strength and battery use." It will also be very stable and reliable, which means that 5G signals will become more stable and reliable than older cell phone signals. 5G has a lot more bandwidth, with peak transmission speeds of more than $1 \mathrm{Gbps}$. This goes some way to explaining why $5 \mathrm{G}$ will make industrial IoT so common and destructive.

\section{iv. MODELING OF PORT}

This section describes how the DUE economic model was applied to the test case with two terminals (each with one endpoint) with varying state of technology ("tech" scenarios). The following are two "tech" scenarios that are compared and contrasted:

- The first is based on the assumption that the two ports use different technologies.

- The other implies that the two ports are connected by a shared PCS.

The function is used to calculate the total time in the two different scenarios. Table 1 shows the values of the variables. The assumptions for the cost equations and demand numbers in the table are now all based on times greater present in current ports.

Table.1. Information of different port

\begin{tabular}{lllll}
\hline & \multicolumn{3}{c}{ Without PCS } & With shared PCS \\
\hline & Port 1 & Port 2 & Port 1 & Port 2 \\
Cp & 500 & 500 & 500 & 500 \\
To,p & 30 & 60 & 30 & 60 \\
$\boldsymbol{\mu}$ & 2 & 2 & 1 & 1 \\
$\boldsymbol{\theta}$ & 4 & 4 & 4 & 4 \\
\hline
\end{tabular}

In other industries, the adoption of PCS has resulted in a 90 percent reduction in time. When comparing the cost savings achieved by using electronic documents to conventional documentation, the difference is around $40 \%$, going from $\$ 4.52$ (digital document with PCS) to $\$ 7.39$ (traditional document). Based on these figures, a 50 percent savings is assumed. To do this, the parameter is set to 2 (system without PCS) and then halved, resulting in a value of 1. (System with PCS). The calculations for the two situations, as specified in Table 1 , are illustrated in Figure 7, which shows plots showing port time for every one of the two ports. Figure 8 shows the 


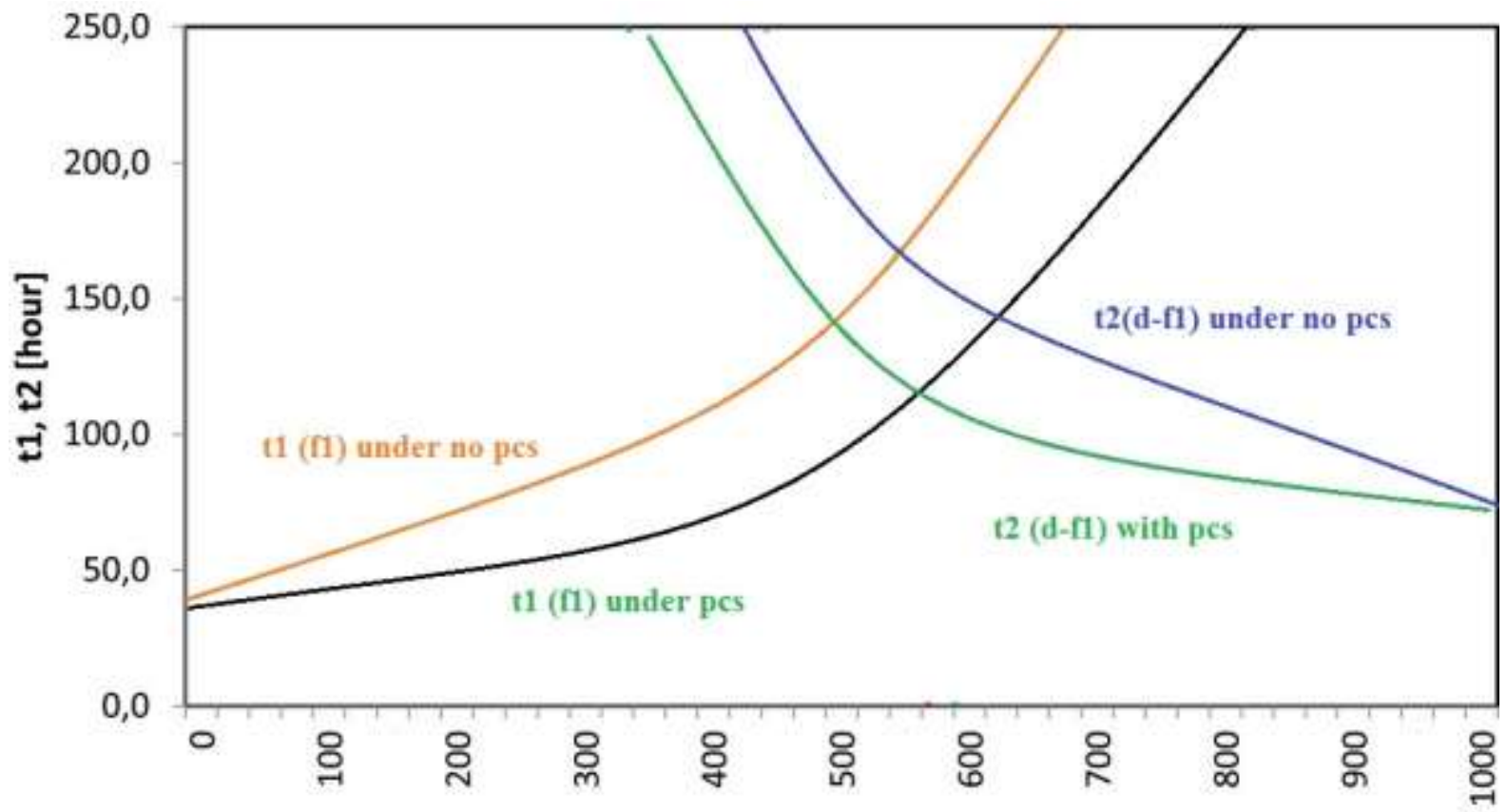

f1, f2 [UL/hour]

Fig.7. Cost function for two ports without and with considering port

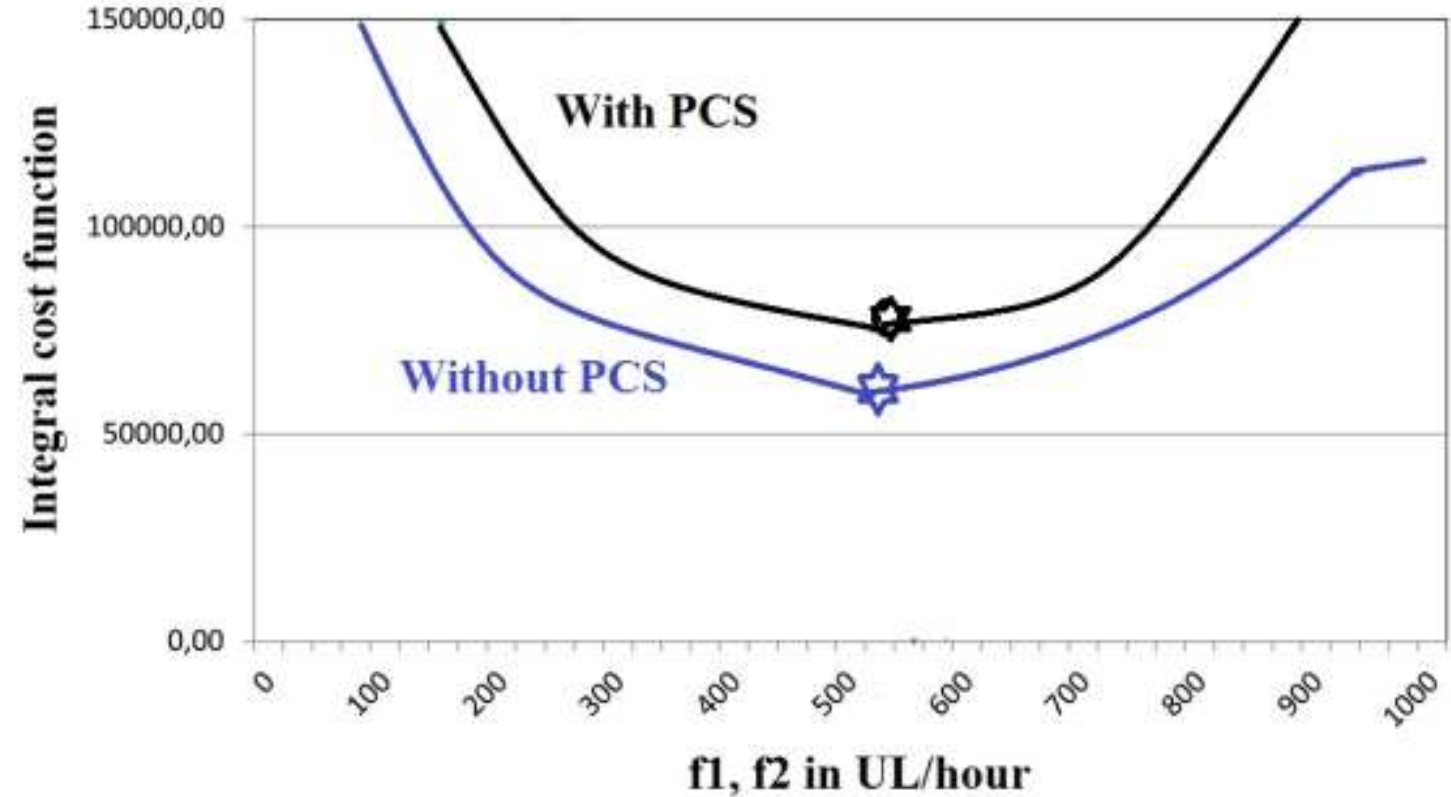

Scenario 1 illustrates that equilibrium is established with a higher value of port duration than the number of port time associated with Scenario 2. Scenario 2's curve always shows lower numbers than Scenario 1, indicating that the establishment of a shared PCS between two ports dictates benefits in terms of reduced port operating time in all conditions.

v. CONCLUSION

The importance of emerging ICT in ports is examined in this article, with a focus on in the next PCSs. After a brief overview whereby the main pillars of terminals are recalled, as specified historically, the current issues associated with integrating a new pillar: emerging ICT incorporated inside PCSs are remembered. The article discusses a unique feature found only in ports and not in other modes of transportation: the existence of work zones where decisions are shared among multiple judgement. Because the efficacy and efficiency of ports are determined by their level of response, which can be assessed using worldwide metrics, the challenge of sharing decisions is critical in ports today The article discusses the many types of job domains and the decision-makers 
that are directly influenced. IoT, BD, BC, AI, and DT are some of the developing ICTs technologies that can help PCSs improve their quality and productivity. After introducing the various work domains, decision call, and PCSs with the growing ICT, the TSMs equations are used to present a unified framework in which the three aspects are merged. The logistics simulation is described as a synchronic graph that represents all port operations. The possibility is addressed with each link that the disutility is caused by a single decision-maker or multiple decision-makers. This is formalized by taking into account each link's body movements and transactions. This method enables simulation in each connection of all task areas that require it. This formulation elucidates the function of PCSs (as updated by growing ICT) in rising utility costs (or in the reduction of times). Those hypotheses allow multiple situations to be simulated, spanning from the absence of developing ICT to the inclusion of PCS that facilitates collaborative decision-making. In this a comparison is carried out where two ports are taken. The assessment reveals the effectiveness without PCS and with PCS.

\section{REFERENCES}

1. Awada, A., Ayari, M. Y., Khenchaf, A., \& Coatanhay, A. (2006). Bistatic scattering from an anisotropic sea surface: Numerical comparison between the first-order SSA and the TSM models. Waves in Random and Complex Media, 16(3), 383-394.

2. Caldeirinha, V., Felício, J. A., Salvador, A. S., Nabais, J., and Pinho, T. (2020). The Impact of Port Community Systems (PCS) Characteristics on Performance. Res. Transportation Econ. 80.

3. Date, K., \& Tanaka, Y. (2021). Quality-Oriented Statistical Process Control Utilizing Bayesian Modeling. IEEE Transactions on Semiconductor Manufacturing.

4. Gattuso, D., Musolino, G., and Perri, V. (2005). Flussi informativi nel porto di Gioia Tauro. In Progetto REPORTS e progetto SESTANTE. D. Gattuso (a cura di). Milano: Collana Trasporti, FrancoAngeli, $167-184$.

5. Heaver, T., Meersman, H., and Van De Voorde, E. (2010). Co-operation and Competition in International Container Transport: Strategies for Ports. Maritime Pol. Management. 28 (3), 293-305.

6. Higgins, M., \& Morgan, J. (2000). The role of creativity in planning: The'creative practitioner'. Planning Practice \& Research, 15(1-2), 117-127.

7. Inoue, S. (2018). Realities and Challenges of Port alliance in Japan - Ports of Kobe and Osaka. Res. Transportation Business Management. 26, 45-55.

8. Martín-Alcalde, E., Saurí, S., and Ng, A. K. Y. (2016). Port-Focal Logistics and the Evolution of Port Regions in a Globalized World, in: Dynamic Shipping and Port Development in the Globalized Economy Volume 2: Emerging Trends in Ports, P. Tae-Woo Lee, and K. Cullinane (eds.). Mcmillan, Palmgrave, pp 102-127

9. Moros-Daza, A., Amaya-Mier, R., and Paternina-Arboleda, C. (2020). Port Community Systems: A Structured Literature Review. Transportation Res. A. 133, 27

10. Russo, F., and Musolino, G. (2020). Quantitative Characteristics for Port Generations: the Italian Case Study. Int. J. TDI. 4 (2), 103-112.

11. Turgut, M. (2015, February). Theory of semiotic mediation in teaching and learning linear algebra: In search of a viewpoint in the use of ICT. In CERME 9-Ninth Congress of the European Society for Research in Mathematics Education (pp. 2418-2424).

12. UNCTAD (1999). Fourth-generation Port: Technical Note. Ports Newsletter N. 19, Prepared by UNCTAD D Secretariat. Geneva, Switzerland. 